\title{
Prevalência e severidade de gengivite em escolares de 7 a 14 anos: condições locais associadas ao sangramento à sondagem
}

\author{
Prevalence and severity of gingivitis among scholars (7-14 years): \\ local conditions associated to bleeding on probing
}

Leandro Chambrone ${ }^{1}$

Sergio Bassit $M$ acedo ${ }^{2}$

Francisco Cardoso Ramalho ${ }^{2}$

Eduardo Trevizani Filho ${ }^{1}$

Luiz Armando Chambrone ${ }^{2}$

${ }^{1}$ Faculdade de O dontologia,

Abstract The objective of this study was to collect data about the prevalence and severity of gingivitis in a sample of scholars, as well as its relationship with possible local risk factors. Two hundred and six subjects were examined, 107 male and 99 female, with age ranging from 7 to 14 years, where data from their Plaque Index (IP), Gingival Index (IG), and Clinical Probing D epth (PCS) were collected. Among all the clinical parameters observed, the mean values found referent to PCS, IP and IG were $1.58 \pm 0.46,1.12 \pm 0.49$ and 0.89 \pm 0.32 , respectively. Ninety five subjects $(46.1 \%)$ presented a diagnostic of slight gingivitis and 111 (53.9\%) of moderate gingivitis. Overall, malesubjectspresented statistically more dental plaqueand more gingival inflammation than female subjects. Clinical signs of gingival inflammation werefound in all the examined subjects. Gingivitis severity around permanent teeth was directly linked to the amount of dental plaque deposits and to the presence of bleeding on probing.

Key words Gingivitis, Gingivitis/epidemiology, Dental plaque, D entition, M ixed, Tooth exfoliation
Resumo 0 objetivo desteestudo foi coletar dados sobre a prevalência e severidade de gengivite em uma amostra de crianças em idade escolar, bem como sua relação com possíveis fatores de risco locais. Duzentos e seis indivíduos foram examinados, sendo 107 meninose 99 meninas, com idades entre 7 e 14 anos; foram coletados dados referentesao índicedeplaca (IP), índicegengival (IG) eprofundidade clínica de sondagem (PCS). Entre os parâmetros clínicos observados, as médias referentes a PCS, IP eIG encontradasforam de 1,58 \pm $0,46,1,12 \pm 0,49$ e 0,89 $\pm 0,32$, respectivamente. Noventa e cinco indivíduos $(46,1 \%)$ apresentaram um quadro de gengivite leve e 111 (53,9\%), degengivite moderada. No geral, os indivíduos do sexo masculino apresentaram estatisticamente maior quantidade de placa bacteriana e maior inflamação do tecido gengival que indivíduos do sexo feminino. A presença de inflamação gengival foi encontrada em todos os indivíduos examinados. A severidade de inflamação nos dentes permanentes esteve diretamente relacionada à quantidade de placa eao sangramento à sondagem. Palavras-chave Gengivite, Gengivite/epidemiologia, Placa dental, D entição mista, Esfoliação de dente 
Introdução

As doenças que afetam os dentes são tão antigas quanto o próprio homem; entretanto, levantamentos epidemiológicos das condições de saúde bucal só tiveram início há algumas décadas. A partir do estudo experimental em humanos sobre a gengivite, realizado por Löe et al. ${ }^{1}$, pode-se observar queo acúmulo de placa bacteriana acarretava 0 desenvolvimento de inflamação gengival (gengivite) e que a sua remoção propiciava a resolução destas lesões. Por sua vez, estes tipos de observações sistemáticas tornaram-seum instrumento importante no entendimento das determinantes que causam as doenças em indivíduos com características semelhantes, contribuindo, assim, para os métodos de prevenção etratamento de diferentes enfermidades².

Deacordo com o Instituto Brasilei ro de Geografia e Estatística ${ }^{3}$, a população brasileira estimada é de 184.597.401 pessoas, sendo que, destas, mais de 27.124 .000 (por volta de $14,7 \%$ ) encontram-se entre os 7 e 14 anos de idade. A pesar deste percentual, poucos estudos sobre as condições gengivais de indivíduos provenientes desta faixa etária são encontrados no país. Além disso, no último levantamento epidemiológico nacional realizado pelo M inistério daSaúde, indivíduos com idades entre 6 e 11 e entre 13 e 14 anos não foram avaliados4.

M altz e Silva ${ }^{5}$ mostraram em seu estudo um declínio na prevalência de cáries ao redor de 70\% em indivíduos com idades entre 8 e 10 anos, ao longo das últimas décadas; contudo, observaram também queas condições gen givais mantiveramse praticamente as mesmas. Gjermo et al. ${ }^{6}$, através de uma revisão sistemática dos estudos sobre as doen ças periodontais realizados nos países da América Central e do Sul, observaram quea gengivite apresenta-se amplamente distribuída entre as crianças eadolescentes, apresentando uma leve tendência a uma maior prevalência entre indivíduos do sexo masculino e provenientes de camadas socioeconômicas mais baixas.

Especificamente no Brasil, alguns trabalhos avaliaram as condições gengi vais entrecriançase adolescentes ${ }^{5,7-13}$. Destes, dois trabal hos realizados em 1998 observaram as condições gengivais entre 811 crianças com idades entre 7 e 14 anos, provenientes de duas classe socioeconômicas diferentes entresi $i^{9,10}$. No primeiro estudo, os autores analisaram e estabeleceram a prevalência e severidade da gengivite em relação à higiene bucal entre 320 escolares, de cor branca, alunos de um estabelecimento de ensino particular, locali- zado na zona sul da cidade de São Paulo, num bairro considerado de classe média-alta. No segundo estudo, os autores repetiram a mesma metodologia em um grupo de 491 crianças, que em sua grande maioria eram moradoras de uma favela. Os resultados de ambos estudos evidenciaram quea prevalência de gengivite foi de praticamente $100 \%$, sendo apenas as amostras diferenciadas conforme o grau de severidade de doença, mais evidentes entre os menos favorecidos.

O objetivo deste estudo foi coletar dados sobre a prevalência e severidade de gengivite em uma amostra de crianças em idade escolar, bem como sua relação com possíveis fatores de risco locais.

\section{Métodos}

População estudada e critério de exclusão

0 presente estudo descritivo de corte transversal foi realizado de forma a coletar dados a respeito das condições gengivais de um grupo de alunos (provenientes de uma classe socioeconômica média-alta) matriculados no Colégio $\mathrm{Me}$ todista, entidade particular localizado no município deSão Bernardo do Campo (SP). Esta unidade encontra-se vinculada à Universidade $\mathrm{Me}$ todista de São Paulo, entidade que permitiu e aprovou o projeto de pesquisa através do seu comitê de ética. Um termo de consentimento escrito foi endereçado a todos os pais ou responsáveis de cada aluno matriculado, de forma a autorizar a participação nesta pesquisa. Os sujeitos foram excluídos quando: a) apresentassem al guma doença sistêmica; b) estivessem em tratamento com antibióticos; c) fossem portadores de problemas motores; d) não receberam autorização dos pais ou responsável; e) possuíam menos de quatro dentes permanentes erupcionados e em oclusão; ou f) estivessem fazendo uso deaparelho ortodôntico fixo ou móvel. No total, 206 indivíduos foram examinados, sendo 107 meninos e 99 meninas, com idades entre 7 e 14 anos (média de 10,26 + 1,88) (Tabela 1). Em suma, a técnica de seleção da amostra foi aleatória e os sujeitos da pesquisa que se apresentassem em acordo com os critérios adotados foram incluídos no estudo.

\section{Avaliação clínica e radiográfica}

A coleta dos dados ocorreu junto a Clínica de Atendimento O dontológico da Disciplina dePerio- 
Tabela 1. Distribuição dos indivíduos conforme a idade e sexo.

\begin{tabular}{crrrrrr}
\hline & \multicolumn{2}{c}{ Sexo masculino } & & \multicolumn{2}{c}{ Sexo feminino } \\
\cline { 2 - 3 } \cline { 5 - 6 } Idade & \multicolumn{1}{c}{$\mathrm{n}$} & $\%$ & & \multicolumn{2}{c}{$\mathrm{n}$} & \multicolumn{1}{c}{$\%$} \\
\hline 7 & 6 & $3 \%$ & & 5 & $2 \%$ \\
8 & 8 & $4 \%$ & & 15 & $7 \%$ \\
9 & 26 & $14 \%$ & & 25 & $12 \%$ \\
10 & 20 & $10 \%$ & & 19 & $9 \%$ \\
11 & 11 & $5 \%$ & & 12 & $6 \%$ \\
12 & 17 & $8 \%$ & & 10 & $5 \%$ \\
13 & 12 & $6 \%$ & & 8 & $4 \%$ \\
14 & 7 & $3 \%$ & & 5 & $2 \%$ \\
Total & 107 & $53 \%$ & & 99 & $47 \%$ \\
\hline
\end{tabular}

dontia, por intermédio de dois especialistas em Periodontia(SBM eFCR) calibradosentresi (com um nível de concordância igual ou superior a 0,70 para os parâmetros observados) que utilizaram espelhos clínicos, sondas exploradoras $n-5$ e de sondas periodontais do tipo Williams. Os seguintes dados clínicos foram anotados: 1) retração gengival (RG), medida dajunção cemento-esmalte à margem gengival; 2) profundidade clínica de sondagem (PCS), medida da margem gengival ao fundo de sulco gengival; 3) perda de inserção clínica (PIC), medida dajunção cemento-esmalte ao fundo do sulco gengival; 4 ) índicedeplaca(IP) ${ }^{14}$; e5) índice gengival $(I G)^{15}$. Radiografias interproximais, duas por paciente, complementaram o exame. Em adição, a mensuração dos dados foi realizada em todos os dentes erupcionados e em oclusão. Dentes decíduos em processo de esfoliação ou permanentes em processo de erupção não foram incluídos.

\section{Diagnóstico das condições gengivais}

Baseado nos valores obtidos através do índice gengival (IG) no momento do exame clínico, cada indivíduo foi classificado conforme a severidade da inflamação gengival ${ }^{15}$ :

- Inflamação gengi val leve: discreta alteração decor evolume, com um IG variando entre 0,1 e 1,0 . 0 sangramento à sondagem pode ou não estar presente;

- Inflamação gengival moderada: alteração de cor, volume etextura, com um IG variando entre 1,1 e 2,0. Presença de sangramento à sondagem;

- Inflamação gengival severa: presença de alterações de volume, textura e cor acentuadas, presença de áreas de ulceração e um IG variando entre 2,1 e 3,0. Presença de sangramento à sondagem e espontâneo.

\section{Análise estatística}

A análise comparativa dos parâmetros clínicos foi executada com auxílio de um programa de estatística para computador ( NCSS ${ }^{\circledR} 2000$ software package, N umber Cruncher Statistical System, NCSS, Kaysville, U tah, USA). M édias edesvios padrão foram calculados de forma a sintetizar os dados coletados. 0 teste-t de Student para dois grupos independentes foi utilizado na comparação dos parâmetros clínicos de profundidade clínica de sondagem, índice de placa e índice gengival, em relação ao sexo. Q uando as variâncias das duas amostras não foram consideradas iguais, o teste de variâncias desiguais de AspinWelsh foi aplicado.

Um segundo teste estatístico, análise de regressão logística, foi realizado de forma a investigar a associação entreidade, sexo, índice de placa, índicegengival, presença de retração gengival, presença dehiperplasia gengival ehábitos de respiração (respiração bucal) com o sangramento gengival. A variável dependentefoi o sangramento à sondagem em dentes permanentes, ou seja, indivíduosqueapresentaram mais de $30 \%$ dos dentes permanentes com sangramento à sondagem. As taxas de probabilidade (odds ratio) com os limites, inferior e superior, de confiança de $95 \%$ (intervalo de confiança) também foram calculados. Diferenças mostrando um nível de probabilidade $p<0.05$ foram consideradas estatisticamentesignificativas.

\section{Resultados}

0 número total de dentes examinados nos 206 indivíduos foi de 4.476 (média de 21,72 $\pm 4,26$ ), sendo 1.242 decíduos e 3.234 permanentes. Entre os parâmetros clínicos observados, as médias referentes a PCS, IP eIG encontradas foram de 1,58 $\pm 0,46,1,12 \pm 0,49$ e $0,89 \pm 0,32$, respectivamente (Tabela 1). As tabelas 2, 3 e 4 apresentam estes três item separados conforme a idade e o sexo.

A prevalência de inflamação gengival, mensurada através da presença do sangramento à sondagem, foi observada em todos os participantes, sendo que $95(46,1 \%)$ apresentaram um quadro degengivitelevee 111 (53,9\%), de gengivite moderada. N enhum caso de gengivitesevera foi encontrado clinicamente, bem como nenhu- 
ma perda das estruturas periodontais foi observada através do exame clínico e radiográfico.

No geral, os indivíduos do sexo masculino apresentaram estatisticamente maior quantidade de placa bacteriana $(p<0,02)$ e mai or inflamação do tecido gengival $(p<0,007)$ do que os do sexo feminino quando comparados através do teste-t de Student. Em relação à profundidade clínica de sondagem, não houve diferenças entre os participantes.

Em adição, pode ser observado também que os indivíduos do sexo masculino, com idade menor ou igual a 10 anos, com o índice de placa maior que 1,0 e o um índice gengival entre 1,0 e 1,3 , apresentaram um maior número de dentes permanentes com sangramento gengival (Tabela 3). Entretanto, o grau de associação entre a variável dependente eos fatores de risco suspeitos foi investigado através de uma segunda análise estatística, de forma a evitar erros na interpretação dos resultados. Os resultados da análise de regressão logística estão apresentados na Tabela 4. As variáveisindependentes IP $(p=0,005)$ eIG ( $p$ $=0,002$ ) mostraram-se relacionadas com o nú-

Tabela 2. Teste-t de Student para as médias e desvios padrão referentes à profundidade clínica de sondagem (PCS), índice de placa (IP) e índice gengival (IG).

\begin{tabular}{lcccccrr}
\hline & \multicolumn{4}{c}{ Sexo } & & Hipótese da variância & \\
\cline { 2 - 4 } & \multicolumn{3}{c}{ Masculino } & \multicolumn{2}{c}{ Feminino } & & \\
PCS & 1,62 & 0,41 & 1,61 & 0,41 & & Iguais & 0,27 \\
IP & 1,18 & 0,11 & 0,95 & 0,25 & & Iguais & $0,02^{*}$ \\
IG & 0,95 & 0,08 & 0,79 & 0,16 & & Diferentes & $0,007^{*}$ \\
\hline
\end{tabular}

*estatisticamente significantes; " 0 obtido através do teste deAspin-Welch.

Tabela 3. Número de indivíduos com inflamação gengival moderada e com mais de $30 \%$ dos dentes permanentes apresentando sangramento à sondagem, conforme os vários fatores analisados.

\begin{tabular}{|c|c|c|c|}
\hline & $\begin{array}{l}\text { Número de } \\
\text { indivíduos }\end{array}$ & $\begin{array}{l}\text { Indivíduos cominflamação } \\
\text { gengival moderada }(1>\mid G \geq 2)\end{array}$ & $\begin{array}{l}\text { Indivíduos apresentando } \\
\text { sangramento a sondagem em mais } \\
\text { de } 30 \% \text { dos dentes permanentes }\end{array}$ \\
\hline \multicolumn{4}{|l|}{ Idade } \\
\hline$\leq 10$ anos & 124 & 41 & 22 \\
\hline$>10$ anos & 82 & 19 & 6 \\
\hline \multicolumn{4}{|l|}{ Sexo } \\
\hline masculino & 107 & 35 & 16 \\
\hline feminino & 99 & 25 & 12 \\
\hline \multicolumn{4}{|c|}{ Índice de placa } \\
\hline$\leq 1$ & 103 & 4 & 32 \\
\hline$>1$ & 103 & 56 & 5 \\
\hline \multicolumn{4}{|c|}{ Índice gengival } \\
\hline$\leq 1,3$ & 146 & 51 & 21 \\
\hline$>1,3$ & 60 & 9 & 7 \\
\hline \multicolumn{4}{|c|}{ Retração gengival } \\
\hline Não & 197 & 55 & 25 \\
\hline Sim & 9 & 5 & 3 \\
\hline \multicolumn{4}{|c|}{ H iperplasia gengival } \\
\hline Não & 192 & 54 & 25 \\
\hline Sim & 14 & 6 & 3 \\
\hline \multicolumn{4}{|c|}{ Respiração bucal } \\
\hline Não & 200 & 56 & 27 \\
\hline Sim & 6 & 4 & 1 \\
\hline
\end{tabular}


Tabela 4. Resultados da análise de regressão logística para os indivíduos apresentando mais de $30 \%$ dos dentes permanentes com sangramento à sondagem

\begin{tabular}{lccccccc}
\hline & $\begin{array}{c}\text { Coeficiente } \\
\text { de regressão }\end{array}$ & $\begin{array}{c}\text { Desvio } \\
\text { padrão }\end{array}$ & $X^{2}$ & $p$ & $\begin{array}{c}\text { Taxas de } \\
\text { probabilidades } \\
\text { (odds ratio) }\end{array}$ & $\begin{array}{c}\text { Intervalo de } \\
\text { confiança 95\% }\end{array}$ & $\begin{array}{c}\text { Último } \\
\mathrm{R}^{2}\end{array}$ \\
\hline Intercepto & $-3,32$ & 0,64 & 26,52 & 0,000 & & 0,18 \\
Idade & $-0,98$ & 0,54 & 3,24 & 0,071 & 0,37 & $(0,12-1,09)$ & 0,01 \\
Sexo & 0,17 & 0,47 & 0,14 & 0,707 & 1,19 & $(0,47-2,99)$ & 0,00 \\
Índice de placa & 1,83 & 0,65 & 7,84 & 0,005 & 6,24 & $(1,73-22,48)$ & 0,03 \\
Índice gengival & 2,18 & 0,73 & 8,85 & 0,002 & 8,89 & $(2,10-37,52)$ & 0,04 \\
Retração gengival & 1,53 & 0,81 & 3,50 & 0,061 & 4,62 & $(0,92-23,05)$ & 0,01 \\
Hiperplasia gengival & 0,68 & 1,08 & 0,39 & 0,970 & 1,98 & $(0,23-16,70)$ & 0,00 \\
Respiração bucal & 0,05 & 1,37 & 0,00 & 0,530 & 1,05 & $(0,07-15,70)$ & 0,00 \\
\hline
\end{tabular}

mero de indivíduos que apresentaram mais de $30 \%$ dos dentes permanentes com sangramento à sondagem, com uma taxa de probabilidade (oddsratio) de 6,24 (I.C. 99\%: 1,15-33,63) e 8,89 (I.C. 99\%: 1,34-38,99), respectivamente. As variáveisidade $(p=0,071)$, sexo $(p=0,707)$, presença de retração gengival ( $p=0,061)$, presença de hiperplasia gengival ( $p=0,97)$ erespiração bucal $(p=0,53)$ não seapresentaram significativamente associadas à variável analisada (sangramento à sondagem em dentes permanentes).

\section{Discussão}

A epidemiologia das doenças gengivais e periodontais está intimamente vinculada à descrição da distribuição das doenças, identificação dos fatores etiológicos e suas consequências e aplicação das informações obtidas pelos estudos no controle dos problemas ${ }^{16}$. A partir da Classificação das Doenças Periodontais proposta em 1999 pela Academia Americana de Periodontologia, criou-se uma categoria somente de doenças gengivais, que até então estavam compreendidas dentro do grupo de doenças periodontais ${ }^{17}$.

0 presente estudo teve como propósito acessar as condições gengivais em um grupo de escolares com idades entre 7 e 14 anos. Das 206 crianças analisadas, todas apresentaram algum sinal de inflamação gengival, ou seja, uma prevalência de $100 \%$. Este resultado apresenta-se em concordância com outros estudos realizados em indivíduos com mesma faixa etária9,10. Dados semelhantes foram observados em outras amostras de crianças e adolescentes provenientes de diferentes localidades ${ }^{5,7-13}$.
Em relação à predominância de sítios com inflamação, pudemos observar que a média obtida através do IG não ultrapassou 1,0, também similar a outras amostras ${ }^{9,10}$. Entretanto, o nível de associação da severidade da doença em relação ao sexo foi avaliada através de análise estatística, fornecida pelo teste-t deStudent. Osindivíduos do sexo masculino apresentaram maior quantidade de placa bacteriana e de inflamação gengival quando comparados aos indivíduos do sexo feminino $(p<0,05)$ (Tabela 2$)$; Cunha e Chambrone $^{9,10}$ observaram o contrário.

A pesar do valor do IG médio, sessenta crianças $(29,1 \%)$ apresentaram-secom diagnóstico de gengivite moderada ( $1<\mathrm{IG} \leq 2$ ). Destas, apenas $28(13,6 \%)$ tiveram o sangramento à sondagem presente em mais de $30 \%$ dos sitos examinados (Tabela 3).

Contudo, estudos deste tipo podem apresentar al gumas condi ções a serem avaliadas. Primeiramente, estudos sobre a mensuração da gengivitepor intermédio de diferentes tipos de índices gengivais e de diferentes examinadores evidenciaram que o número de sítios com sangramento em cada indivíduo não se altera através da manipulação de diferentes examinadores ${ }^{18}$.

Segundo, o estágio de dentição mista, compreendido entreos 6 e 11 anos, em que seencontra a maioria dos participantes desta amostra, pode ser enfocado como um problema em potencial na mensuração do sangramento à sondagem. Nestes indivíduos, as condições gengivais são afetadas pela esfoliação dos dentes decíduos e pela erupção dos dentes permanentes ${ }^{19}$. Assim sendo, de forma a minimizar possíveis vieses na análise dos dados coletados, a variável presença de sangramento gengival foi analisada, separa- 
damente, apenas em dentes permanentes em oclusão. Para avaliar a influência das variáveis independentesidade, sexo, índice de placa, índicegengival, presença de retração gengival, presença de hiperplasia gengival ou tipo de respiração, utilizou-se uma análise de regressão logística (Tabela 4). Os resultados da análise estatística mostraram que apenas o índice de placa e o índice gengival foram estatisticamente significantes $(p<0.05)$.

Terceiro, apesar de Gjermo et al. ${ }^{6}$ (através de uma revisão sistemática da literatura em levantamentos epidemiológicos conduzidos em países latino-americanos) terem observado que a prevalência degengi vite costuma ser maior entreindivíduos provenientes de classes socioeconômicas mais baixas, pudemos observar que a totalidade de indivíduos analisados apresentaram-se com uma ou mais áreas de inflamação gengival, semel hante aos achados obtidos por Cunha e Chambrone $^{9,10}$.

Quarto, a despeito da alta prevalência de inflamação encontrada nesta amostra e da relação significativa entrea gen givite visível eo desenvolvimento e a progressão da periodontite, nem todos os sítios com sangramento, mesmo em indivíduosjovens com maior suscetibilidade à doença periodontal, irão desenvolver perda de inserção, uma vez que a periodontite resulta de uma complexa inter-relação entre agentes infecciosos e fatores ligados ao hospedeiro (fatores adquiridos, ambientais ou genéticos), que podem modificar a expressão da doença, afetando tanto 0 seu surgimento, quanto a sua progressão $0^{20,21}$. Contudo, faz-se necessário tratar todas as áreas degengivite deforma a evitar a perda de inserção em sítios mais susceptíveis.

\section{Conclusões}

A presença de inflamação gengival foi encontrada em todos os indivíduos examinados, estando a severidade de inflamação nos dentes permanentes diretamente relacionada à quantidade de placa e ao sangramento à sondagem. Este conjunto de dados nos permite concluir que a prevalência das doenças gengivais continua alta (dentro da faixa etária examinada) e independe do status socioeconômico, estando diretamente associada à higiene oral deficiente.

Desta forma, dentro do grupo estudado, fazse necessário a tomada de estratégias para a modificação do quadro clínico apresentado. A criação de programas de preven ção baseados no controle do biofilme dental e na motivação continuada dos participantes são recursos simples e eficazes que poderão ser capazes de prevenir e interceptar o curso da maior parte das doenças gengivais.

\section{Colaboradores}

SB M acedo e FC Ramalho foram examinadores da amostra; E Trevizani Filho participou como co-orientador; L Chambrone realizou o levantamento das referências, redação do artigo, execução da análise estatística e revisão dos dados coletados e LA Chambrone foi 0 orientador. 


\section{Referências}

1. Löe $H$, Theilade $E$, Jensen SB. Experimental gingivitis in man. J Periodontol 1965; 36:177-187.

2. Davey Smith G, Ibrahim S. Epidemiology - is it time to call it a day? Int J Epidemiol 2001; 30:1-11.

3. Instituto Brasileiro de Geografia e Estatística. [site da Internet] [acessado 2005 set 23]. Disponível em: http://www.ibge.gov.br

4. Projeto SB Brasil 2004. Condições de saúde bucal da população brasileira. [acessado 2005 set 23]. Disponível em: http://www.abonac.org.br/internas/ download/arquivos/r_sb brasil.doc

5. Maltz M, Silva BB. Relaçã̃o entre cárie, gengivite e fluorose e nível socioeconômico em escolares. Rev. Saude Publica 2001; 35:170-176.

6. Gjermo P, Rösing CK, Susin C, Oppermann R. Periodontal disease in Central and South America. Periodontol 2000; 29:70-78.

7. Dini EL, Foschini ALR, Brandão IMG. Periodontal conditions in a 7-19-year-old student population in Araraquara, Sao Paulo, Brazil, 1995. Cad Saude Publica 1997; 13:321-324.

8. Coutinho TCL, Tostes Amaral MA. Prevalência de gengivite em crianças. RGO 1997; 45:170-174.

9. Cunha ACP, Chambrone LA. Prevalência de gengivite em crianças. Rev. Periodontia 1998; 7:1-5.

10. Cunha ACP, Chambrone LA. Prevalência de gengivite em crianças de um nível social baixo. Rev. Pe riodontia 1998; 7:6-10.

11. Marcantonio Júnior E, Santos FA. Avaliação das condições e necessidades de tratamento periodontal em escolares da zona rural, da região noroeste do estado de São Paulo - Brasil. Rev O dontol UNESP 1998; 27:449-458.

12. Silva $B B, M$ altz $M$. Prevalência de cárie, gengivite $e$ fluorose em escolares de 12 anos de Porto Alegre RS Brasil, 1998/1999. Pesqui Odontol Bras 2001; 15:208-214.
13. Cangussu MCT, Coelho EO, Castellanos Fernandes RA. Epidemiologia e iniqüidade em saúde bucal aos 5, 12 e 15 anos de idade no município de Itatiba, São Paulo, 2000. Rev Fac Odontol Bauru 2001; 9:77-85.

14. Silnesss J, Löe H. Periodontal disease in pregnancy. II. Correlation between oral hygiene and periodontal condition. Acta Odontol Scand 1964; 24:747-759.

15. Löe $H$. The gingival index, the plaque index and the retention index systems. J. Periodontol 1967; 38:610-616.

16. Baelum V, Scheutz F. Periodontal diseases in Africa. Periodontol 2000; 29:79-103.

17. Armitage GC. Development of a classification system for periodontal diseases and conditions. Ann Periodontol 1999; 4:1-6.

18. Bollmer BW, Sturzenberger OP, Lehnhoff RW, Bosma ML, Lang NP, Mallatt ME, M eckel AH. A comparison of three clinical indices for measuring gingivitis. J Clin Periodontol 1986; 13:392-395.

19. Stamm JW. Epidemiology of gingivitis. J Clin Periodontol 1986; 13:360-366.

20. Page RC, Offenbacher $S$, Schoroeder HE, Seymour GJ, Kornman KS. Advances in the pathogenesis of periodontitis: summary of developments, clinical implications and future directions. Periodontol 2000; 14:216-248

21. Albandar JM, Kingman A, Brown LJ, Löe H. Gingival inflammation and subgengival calculus as determinants of disease progression in early-onset periodontitis. J Clin Periodontol 1998; 25:231-237.

Artigo apresentado em 17/08/2006

Aprovado em 03/04/2007

Versão final apresentada em 13/04/2007 